JOURNAL BUSINESS, ECONOMIC AND ENTREPRENEURSHIP

https://journal.shantibhuana.ac.id/index.php/bee/index JBEE Volume 3 No 12021

\title{
Positioning Flower Bouquet dengan Multidimensional Scaling Berdasarkan Persepsi Konsumen di Lacherie Florist
}

\author{
Yolanda Octavalery ${ }^{1)}$, Christy Dwita Mariana ${ }^{2)}$, Dionisius Yusuf ${ }^{3)}$ \\ Universitas Agung Podomoro ${ }^{1,2}$ \\ Institut Shanti Bhuana ${ }^{3)}$ \\ christy.mariana@podomorouniversity.ac.id \\ dionisius.yusuf@shantibhuana.ac.id
}

Received: 30 Maret 2021; Accepted: 31 Maret 2021; Published: 30 April 2021

\begin{abstract}
The purpose of this study is to determine the position of flower bouquet on the consumer perception in Lacherie Florist by using multidimensional scaling analysis (MDS). The sample in this research were 104 respondents of Lacherie Florist. Data collection used a questionnaire through Google forms. The validity test results stated that all statements were valid as well as the reliability test showed that all parameters were reliable. The results obtained from the bouquet flower were divided into four different positioning groups based on consumer perception. The results indicated that (1) Bloom Box was most different from other types of bouquet flower (2) Bloom Bag, Artificial Flowers and Snack Bouquet have similarities because they were in the same quadrant (3) Mixed Money and Flowers and Money Bouquet were the most similar type because of the position closest to each other. (4) Fresh flowers have similarities with Mix Money Bouquet and Flowers but located in different quadrant.
\end{abstract}

Keywords: Bouquet flower, consumer, perception, multidimensional scaling, positioning 


\section{PENDAhULUAN}

Pandemi Covid-19 yang terjadi pada saat ini membuat orang lebih inovatif. Keterbatasan diakibatkan adanya pandemi justru membuat banyak orang makin kreatif, termasuk tumbuhnya beberapa industri kreatif. Ditengah wabah Covid-19, terdapat beragam jenis peluang usaha yang bermunculan dan saling bersaing satu sama lainnya. Salah satunya adalah industri kreatif di bidang floriikultura.

Tinaprilla dan Pratiwi (2017) dalam bukunya yang berjudul "Menuju Agribisnis Indonesia yang Berdaya Saing" menyatakan bahwa salah satu industri yang belum dapat dimanfaatkan secara maksimal namun memiliki potensi yang sangat besar adalah industri agribisnis. Industri agribisnis florikultura adalah seluruh kegiatan bisnis yang berhubungan erat dengan perbungaan. Industri ini memiliki peluang yang cukup tinggi dikarenakan industri pariwisata dan bisnis yang kian meningkat di banyak wilayah di Indonesia. Dengan peningkatan tersebut, tidak heran jika cukup banyak masyarakat yang pada akhirnya menggunakan produk florikultura sebagai bagian dari kehidupan mereka.

Sa'diyah (2017) menyatakan bahwa di banyak negara, industri florikultura mampu berkontribusi besar terhadap PDB. Lebih lanjut Sa'diyah mengungkatkan bahwa industri florikultura dapat berkembang cukup pesat. Beberapa hal yang dapat dilakukan untuk mengembangkan industri ini yaitu dengan cara memperluas area pertanaman, peningkatan produksi dan produktivitas. Menurut Direktorat Jenderal Holtikultura Kementrian Pertanian, Produk Domestik Bruto (PDB), industri florikultura pada periode 2010-2017 mencapai lebih dari 7 triliun atau meningkat sekitar $12 \%$. Nilai ekspor mencapai 20 juta US Dollar yang mana mengalami peningkatan sekitar 5-12\% setiap tahun (Tarigan, 2017).

Florikultura merupakan salah satu cabang ilmu dari hortikultura yang mempelajari tentang tanaman hias. Contoh nya seperti bunga potong, daun potong, tanaman dalam pot atau tanaman untuk menghias taman. Saat ini, bunga potong menjadi salah satu produk florikultura yang sedang digermari. Hal ini ditunjukkan dengan peningkatan penggunaan bunga potong Menurut Puspitasari (2015) setiap tahunnya industri bunga potong di Indonesia mengalami peningkatan sebesar 8 persen.

Menurut Nasti (2013), pilihan untuk berkecimpung dalam industri agribisnis florikultura merupakan pilihan yang tepat karena memiliki prospek pasar yang besar, sehingga dapat menjanjikan laba yang besar pula. Dalam buku "Laporan Kinerja Direktorat Jenderal Hortikultura TA. 2017", Sujono (2018) pada tahun 2017, target produksi tanaman hias dan bunga potong adalah 803.824.652 tangkai, sedangkan produksi tanaman daun hias dan bunga potong pada tahun tersebut mencapai 809.079.946 tangkai, yang berarti jumlah produksi tanaman daun hias dan bunga potong melebihi target atau sekitar $106.65 \%$. Hal ini memperlihatkan trend positif tanaman hias daun dan bunga potong.

Bunga potong biasanya dipergunakan pada saat perayaan penting seperti pesta pernikahan, peresmian suatu perusahaan, acara kelahiran ataupun perayaan keagamaan. Meskipun demikian bunga potong juga dapat dirangkai menjadi menjadi lebih bervariasi sepeti buket tangan, bunga meja, bunga box sebagai pemberian hadiah kepada seseorang yang berharga, ungkapan cinta kasih kepada lawan jenis, ucapan terimakasih, bahkan ucapan bela sungkawa. Dengan bertambahnya penggunaan bunga potong, maka munculah peluang bagi para pembisnis untuk masuk dalam industri florikultura yang biasanya dilakukan oleh pengusaha bunga atau kerap disebut dengan florist. Cangkupan pasar florist terbilang luas dan berprospek tinggi (Puspitasari, 2015).

Lacherie Florist merupakan usaha florist yang bergerak dalam bidang jasa, juga merupakan salah satu pemain baru yang memberanikan diri untuk masuk dalam persaingan ketat pada era bisnis saat ini. Agar dapat bersaing, Lacherie Florist perlu melakukan tindakan untuk meningkatkan penjualan, salah satunya dengan mengetahui positioning dari masing-masing produk yang dihasilkan oleh Lacherie Florist.

Salah satu metode yang dapat digunakan dalam menganalisis hasil persepsi konsumen adalah dengan menggunakan atribut-atribut dalam pendekatan positioning dan juga penggambaran posisi sebuah obyek satu dengan obyek lainnya menggunakan multidimensional scaling.

Terdapat beberapa penelitian terdahulu yang menjadi acuan dalam penelitian ini, diantaranya penelitian yang dilakukan oleh 
Putri dkk (2018) yang menganalisis positioning top 5 brand smartphone berdasarkan persepsi konsumen di kota Samarinda, Kalimantan Timur. Hasil penelitian menunjukkan bahwa diantara lima lima merek ponsel pintar, Xiaomi memiliki keunggulan pada harga yang paling terjangkau. Keunggulan Samsung adalah pada atribut hasil tampilan layar yang bagus, merek yang lebih dikenal, desain yang lebih cantik, fitur yang lengkap, Kemudahan penggunaan, dan kapasitas memori yang besar. Ponsel pintar Merk Asus, Oppo dan Sony memiliki keunggulan pada hasil kamera yang bagus dan prosesor yang bagus kinerjanya.

Ramadhan (2015) dalam penelitiannya tentang positioning top 4 brands martphone Cina berdasarkan persepsi konsumen di kota Bandung menunjukkan bahwa berdasarkan peta positioning smartphone, smartphone Huawei memiliki pesaing terdekat yaitu smartphone Lenovo. Sedangkan pesaing terdekat smartphone Lenovo adalah smartphone Oppo, dan pesaing terdekat smartphone Xiaomi adalah smartphone Oppo. Sementara berdasarkan 11 atribut yang digunakan, smartphone Oppo dipersepsikan paling baik oleh konsumen, diikuti oleh Lenovo, Huawei, dan yang terakhir Xiaomi.

Penentuan posisi suatu produk berarti bagaimana suatu produk dapat menempati posisi yang khas sesuai dengan keinginan konsumen dalam benaknya. Pemasar perlu mengembangkan posisi pasar yang unik dibandingkan dengan pesaing lain. Apabila suatu produk dianggap sama persis sepeti yang lain di pasaran, maka kemungkinan besar konsumen tidak akan membelinya karena dianggap tidak memiliki nilai lebih.

Menurut Sutojo (2009), positioning sebagai tindakan menempatkan diri secara tepat di setiap segmen pasar, dilakukan dengan jalan membandingkan kekuatan dan kelemahan perusahaan dengan perusahaan pesaing yang beroperasi dalam segmen pasar yang sama.

Menurut Hasan (2008), paling tidak ada 8 pendekatan yang dapat digunakan untuk melakukan positioning yaitu: 1). Menentukan produk atau pasar yang relevan; 2). Pendataan kebutuhan pelanggan; 3). Identifikasi pesaing; 4). Menentukan standar evaluasi; 5). Membuat perceptual map; 6). Identifikasi kesenjangan posisi; 7). Merencanakan dan melaksanakan strategi positioning, dan 8). Memantau posisi.
Persepsi konsumen adalah proses seseorang dimulai dari aktivitas memilih, mengorganisasikan, dan menginterpretasikan rangsangan yang diterima sehingga konsumen mampu mengartikan suatu obyek (Schiffman, Kanuk, \& Wisenblit, 2010). Sedangkan menurut Kotler dan Armstrong (2003) persepsi adalah proses di mana dengan proses itu orang-orang memilih, mengorganisasi, dan menginterpretasi informasi untuk membentuk gambaran yang berarti mengenai dunia. Lebih lanjut Kotler dan Armstrong menyatakan bahwa individu bertindak dan bereaksi atas dasar persepsi, tidak atas dasar realitas obyektif. Karena itu bagi pemasar, persepsi konsumen jauh lebih penting dari pengetahuan mereka tentang realitas obyektif. Apa yang konsumen pikirkan menjadi dasar pada tindakan mereka.

Menurut Gudono (2014), multidimensional scaling (MDS) merupakan teknik algoritma yang berguna untuk mengidentifikasi dimensi mendasari evaluasi atas objek atau untuk menentukan fitur dasar objek yang diamati. MDS atau disebut juga perceptual mapping adalah suatu prosedur yang memungkinkan seorang peneliti menentukan citra relatif yang dilihat pada seperangkat objek, misalnya produk, perusahaan, atau hal lain yang berhubungan dengan persepsi. Perbedaan persepsi di antara semua objek direfleksikan di dalam jarak relatif di antara objek-objek tersebut di dalam suatu ruangan multidimensi.

\section{METODE PENELITIAN}

Jenis penelitian yang digunakan adalah penelitian kuantitatif. Selain melakukan penelitian kuantitatif, peneliti juga menggunakan pendekatan penelitian secara deskriptif. Penelitian deskriptif adalah penelitian yang bertujuan untuk mendeskripsikan atau menggambarkan fenomena yang ada, baik fenomena alamiah maupun rekayasa manusia, dengan tujuan membuat pencandraan secara sistematis, faktual, dan akurat mengenai fakta dan sifat populasi atau daerah tertentu.

Pada penelitian ini, peneliti mengumpulkan data di wilayah Jakarta Barat dan Jakarta Pusat. Peneliti melakukan pengumpulan data di kedua wilayah tersebut dikarenakan keterbatasan peneliti untuk mengumpulkan data di wilayah lain selain kedua wilayah tersebut. Waktu 
penelitian dilakukan dari bulan Januari sampai Juli 2020.

Dalam penelitian ini variabel/kriteria yang ingin diteliti yaitu: 1). Harga yang ditawarkan terjangkau; 2). Kualitas yang diberikan sesuai dengan keinginan; 3). Warna dan jenis setiap item dirangkai sesuai pesanan; 4). Bentuk design wrapping sesuai dengan permintaan; 5). Design wrapping dirangkai dengan rapi; 6). Hasil keseluruhan rangkaian baik dan tertata rapi; 7). Hasil keseluruhan rangkaian sesuai dengan ekspektasi, dan 8). Adanya keinginan untuk pembelian ulang.

Kedelapan variabel tersebut lalu dihubungkan dengan persepi konsumen terhadap tujuh jenis produk yang dihasilkan oleh Lacherie Florist. Adapun tujuh produk yang diuji dalam penelitian ini adalah Fresh Flowers, Artificial Flowers, Snack Bouquet, Money Bouquet, Mix Money and Flowers Bouquet, Bloom Box, dan Bloom Bag.

Dalam penelitian ini teknik pengambilan sampel yang dilakukan adalah dengan teknik purposive sampling. Penelitian ini menggunakan data primer dan data sekunder. Data primer diambil dari hasil kuesioner yang dibagikan kepada konsumen Lacherie Florist. Data sekunder berasal dari berbagai sumber seperti buku, jurnal, dan penelitianpenelitian literatur terdahulu yang bersumber dari internet.

Pengujian validitas ini menggunakan Pearson Correlation, sedangkan pengukuran nilai reliabilitas menggunakan nilai Cronbach's Alpha. Analisis multidimensional scalling (MDS) digunakan untuk menggambarkan persepsi konsumen dalam kedalam sebuah tampilan berbentuk peta. Tujuan penggunaan teknik MDS adalah untuk memberikan gambaran mengenai kemiripan atau jarak di antara objek-objek yang diteliti. Hasil yang diperoleh yaitu dapat berupa posisi persaingan antar objek dan persepi konsumen. Pasangan objek dengan jarak yang dekat dianggap memiliki kemiripan, lalu apabila jaraknya jauh dianggap memiliki banyak perbedaan.

\section{HASIL DAN PEMBAHASAN}

Pada penelitian ini, instrumen yang digunakan adalah kuesioner. Instrumen kuesioner digunakan untuk mengukur positioning flowers bouquet.

Uji validitas diperlukan untuk mengetahui jika sebuah pertanyaan ataupun pernyataan pada kuesioner dapat memberikan hasil ukuran yang diharapkan. Pertanyaan atau pernyataan yang ada di dalam kuesioner tersebut akan diuji terhadap faktor - faktor yang terkait. Pengujian validitas dapat dikatakan memiliki validitas yang tinggi jika tes tersebut menjalankan fungsi ukurnya, atau mampu memberikan hasil ukur yang tepat dan akurat sesuai dengan maksud dilakukannya tes tersebut. Hasil pengujian validitas menunjukan bahwa pernyataan 1 sampai 8 yang diujikan dalam penelitian ini adalah valid dengan nilai $r$-hitung $>$ nilai $r-$ tabel.

Uji reliabilitas bertujuan untuk mengukur hasil kuesioner dengan indikator variabel untuk mengetahui konsistensi dan stabilitasnya. Suatu kuesioner dapat dikatakan reliabel jika jawaban seseorang terhadap pernyataan atau pernyataan konsisten/stabil dari waktu ke waktu. Pengujian dengan reliabilitas tinggi adalah pengukuran yang dapat menghasilkan data yang reliabel. Hasil pengujian reliabilitas menunjukkan nilai Cronbach's Alpha untuk seluruh variabel di atas 0,6 . Hasil tersebut menunjukkan bahwa hasil kuesioner penelitian reliabel.

\section{Demografi Responden}

Hasil penelitian menunjukkan bahwa mayoritas responden adalah wanita $(57 \%)$, dan sisanya adalah lakilaki (43\%). Hasil ini tidaklah mengejutkan karena wanita memang lebih identic dan menyukai produk flower bouquet dibanding pria. Menurut Rawi (2018), wanita lebih tertarik dengan bunga karena memiliki nilai keindahan, harum dan memiliki makna yang unik sesuai dengan jenis bunganya. Sedangkan laki-laki cenderung membeli bunga karena ingin memberikan hadiah kepada pasangan wanitanya.

Sebagian besar responden berada di rentang usia 21-25 tahun. Presentase terbesar ada pada responden dengan usia 22 tahun. Hasil penelitian dari Rawi (2018) juga menunjukan bahwa mayoritas penggemar flower bouquet adalah konsumen kaum usia muda yang berada di rentang usia seperti yang didapatkan oleh peneliti. Usia menjadi suatu hal yang penting karena 
perbedaan usia mempengaruhi konsumen terhadap selera dan preferensi bunga yang dibeli.

Mayoritas responden memiliki pendidikan terakhir S1 yaitu sebesar $64 \%$, dan sisanya SMA dan lebih rendah sebesar 36\%. Hasil penelitian dari Sofiani (2008) juga menunjukan bahwa mayoritas pendidikan terakhir responden yaitu berpendidikan sarjana. Hal ini dikarenakan masyarakat Indonesia umumnya memiliki pendidikan akhir sarjana.

Hasil penelitian memperlihatkan bahwa pekerjaan responden didominasi oleh pelajar/mahasiswa dengan persentase $42 \%$. Tingginya persentase tersebut dikarenakan pelajar/mahasiwa sangat tanggap terhadap tren terbaru, berlaku juga dengan flower bouquet. Oleh sebab itu, dalam pemberian hadiah kepada orang lain, mereka lebih tertarik memberikan buket bunga (Rawi, 2018).

Berdasarkan hasil penelitian, mayoritas responden memiliki pendapatan per bulannya 1-3,99 juta yaitu berjumlah 33 orang atau sebanyak $32 \%$. Tingkat pendapatan akan mempengaruhi konsumen dalam pembelian flower bouquet. Menurut Rawi (2018), tingkat pendapatan secara langsung mampu mempengaruhi konsumen dalam pola konsumsi dan proses keputusan pembelian.

Hasil penelitian juga memperlihatkan bahwa mayoritas responden bersedia mengeluarkan uang untuk pembelian satu kali flower bouquet di harga Rp. 300.000 sebesar $20 \%$ atau berjumlah 21 orang dari total 104 responden. Tiap responden memiliki tingkat pengeluaran yang berbedabeda tergantung dari kebutuhan dan biaya hidup mereka (Sofiani, 2008). Responden yang membeli flower bouquet pun tergantung dari tingkat pengeluaran, kebutuhan, dan keinginan mereka terhadap flower bouquet untuk diberikan sebagai hadiah kepada orang lain

\section{Uji Multi-Dimensional Scalling}

Analisis MDS (multidimensional scaling) dilakukan didasarkan atas kesamaan atau data similarity yang diperoleh dari data kuesioner hasil jawaban responden yang kemudian diolah untuk melakukan pemetaan posisi beberapa produk flower bouquet Lacherie Florist berdasarkan atribut-atribut yang diteliti. Terdapat delapan atribut yang diteliti dalam penelitian ini. Uji MDS digunakan untuk membedakan serta mengukur persepsi konsumen dalam memposisikan ke-7 produk yang dihasilkan oleh Lacherie Flroist terhadap konsumen yang berdomisili di Jakarta.

Peta konfigurasi dua dimensi seperti yang disajikan pada Gambar 1 memperlihatkan persepsi konsumen terhadap beberapa produk Lacherie Florist dan hubungan antara atribut-atribut produk yang diuji dengan MDS.

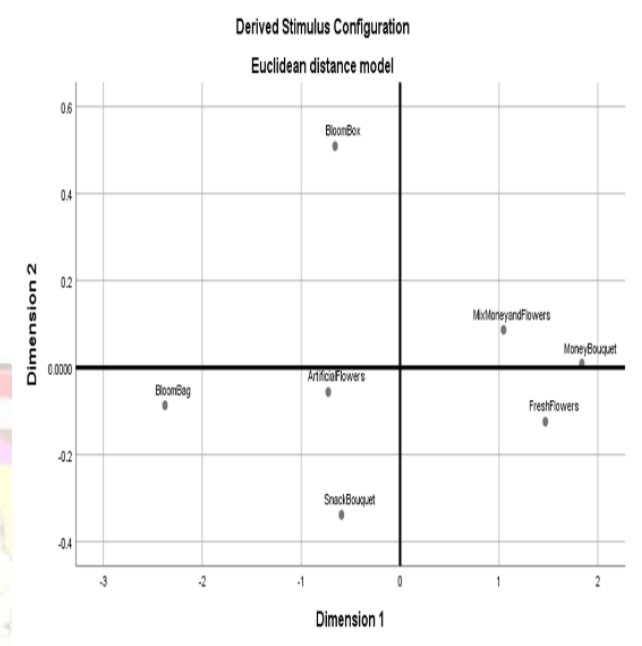

Gambar 1. Peta konfigurasi dua dimensi posisi flower bouquet berdasarkan persepsi konsumen.

Perceptual map seperti yang disajikan di Gambar 1 melambangkan tingkat kemiripan. Semakin dekat jaraknya, semakin mirip atau serupa jenis produk flower bouquet tersebut di mata para konsumen. Berdasarkan peta posisi dari uji MDS, maka dapat dijelaskan sebagai berikut:

1. Posisi peta memperlihatkan bahwa dari ke 7 jenis produk flower bouquet, terdapat 4 pengelompokkan yang berbeda.

2. Jenis flower bouquet mix money and flowers memiliki kemiripan dengan money bouquet karena letak paling berdekatan dan berada pada kuadran yang sama. fresh flowers juga memiliki kemiripan karena letaknya yang cukup dekat dengan keduanya, namun berada pada kuadran yang berbeda. 
3. Jenis flower bouquet bloom bag, artificial flowers, dan snack bouquet memiliki kemiripan karena letaknya cukup berdekatan dan berada pada kuadran yang sama.

4. Jenis flower bouquet bloom box terletak paling jauh dari ke 6 jenis lainnya, maka dari itu dapat dikatakan bahwa jenis bloom box paling berbeda diantara semua jenis flower bouquet lainnya.

Untuk memudahkan identifikasi tiap jenis flower bouquet, maka penelitian ini menggunakan model 2 dimensi yang digunakan untuk menjelaskan hasil dari uji MDS tersebut.

Dimensi 1: berdasarkan perceptual map terlihat bahwa semakin ke kanan, maka angka dimensi 1 semakin besar pula. Jenis flower bouquet mix money and flowers, money bouquet, dan fresh flowers berada paling dekat dengan angka dimensi 1 yang terbesar (terletak di ujung kanan garis horizontal). Hal ini dapat diartikan bahwa ketiga jenis tersebut memiliki faktor-faktor yang mampu membedakan mereka dengan jenis flower bouquet lainnya. Faktor untuk dimensi 1 terkait dengan skala penjualan (terbesar) berdasarkan kecenderungan minat konsumen terhadap tiap jenis flower bouquet yang disediakan.

Dimensi 2: berdasarkan perceptual map terlihat bahwa semakin ke atas, maka angka dimensi 2 semakin besar pula. Jenis flower bouquet bloom box berada paling dekat dengan angka dimensi 2 yang terbesar (terletak di ujung atas garis vertikal). Hal ini dapat diartikan bahwa bloom box merupakan jenis yang memiliki faktor yang sangat berbeda dibandingkan dengan jenis flower bouquet lainnya. Sedangkan bloom bag, artificial flowers dan snack bouquet berada di posisi tengah bawah dimensi 2 dan memiliki kemiripan karena letaknya yang cukup berdekatan. Faktor yang menentukan untuk dimensi 2 yaitu terkait dengan harga yang ditawarkan kepada pembeli. Semakin ke atas semakin mahal, begitu pula sebaliknya semakin ke bawah harganya semakin terjangkau.

\section{Keselarasan Konsumen Dalam Memberi Penilaian}

Hasil yang disajikan pada Gambar 2. memperlihatkan bahwa titik-titik koordinat tidak menyebar ke segala macam arah dan tidak membentuk kelompok-kelompok tersendiri, titik-titik tersebut relatif berkumpul dan membentuk satu garis lurus. Hal ini dapat membuktikan bahwa adanya kesamaan persepsi dari konsumen Lacherie Florist terhadap atribut produk yang ditanyakan. Hasil ini juga memperkuat uji validitas dan realibitas yang dilakukan oleh penulis dimana data yang diperoleh adalah valid dan reliabel.

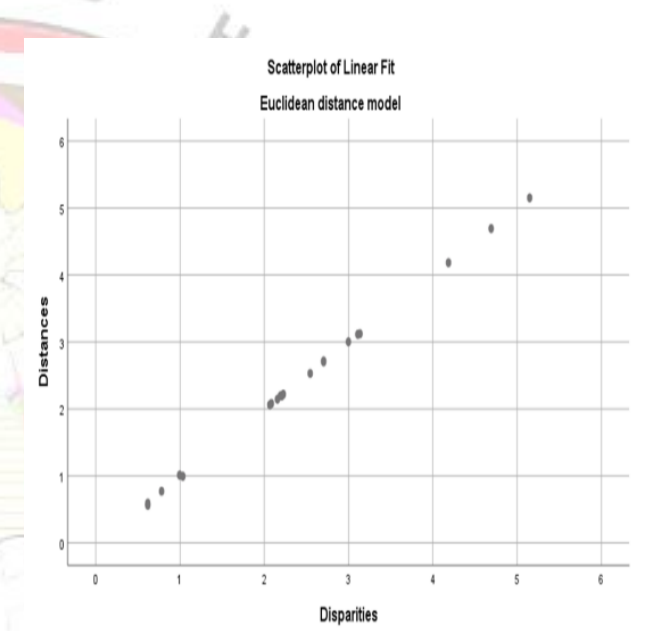

Gambar 2. Peta keselarasan konsumen dalam memberi penilaian

Hasil yang disajikan pada Gambar 2 . memperlihatkan bahwa titik-titik koordinat tidak menyebar ke segala macam arah dan tidak membentuk kelompok-kelompok tersendiri, titik-titik tersebut relatif berkumpul dan membentuk satu garis lurus. Hal ini dapat membuktikan bahwa adanya kesamaan persepsi dari konsumen Lacherie Florist terhadap atribut produk yang ditanyakan. Hasil ini juga memperkuat uji validitas dan realibitas dimana data yang diperoleh adalah valid dan reliabel.

\section{KESIMPULAN}

Berdasarkan uji MDS maka pengelompokkan produk Lacherie Florist adalah sebagai berikut:

Kelompok 1: Bloom Box. Produk Bloom box adalah jenis flower bouquet yang paling berbeda diantara jenis lainnya.

Kelompok 2: Bloom Bag, Artificial Flowers, dan Snack Bouquet. Ketiga jenis flower bouquet memiliki kemiripan karena terletak dalam kuadran yang sama.

Kelompok 3: Mix Money and Flowers dan Money Bouquet. Kedua jenis flower bouquet ini merupakan jenis yang paling mirip karena letak posisinya yang paling berdekatan satu sama lain. Letak posisinya 
yang berada di ujung kanan dimensi 1 dan di tengah-tengah dimensi 2

Kelompok 4: Fresh Flower. Produk Fresh flower termasuk dalam kategori jenis flower bouquet terlaku kedua. Letak posisinya yang berada di kanan dimensi 1 dan di tengah-bawah dimensi 2.

\section{REFERENSI}

Gudono. (2014). Analisis Data Multivariat Edisi Ketiga. BPFE, Yogyakarta.

Hasan, A. (2008). Markerting. Yogyakarta: Media Pressindo.

Kotler, P., Armstrong, G., \& Burton, S. (2013).Pemasaran. Edisi ke-9. Pearson, UK.

Nasti, Y. (2013). Analisis Risiko Produksi Krisan Potong Pada Pembibitan Perusahaan Natalia di Kecamatan Tenjolaya, Kabupaten Bogor. Bogor: Institute Pertanian Bogor.

Puspitasari, R. (2015). Analisis Kelayakan Usaha Bunga Rangkaian (Florist) pada Jelita Florist di Kota Bekasi. Bogor: Institut Pertanian Bogor.

Putri, D.S., Wahyuningsih. S, dan Goejantoro, R. (2018). Analisis Positioning Menggunakan Multidimensional Scalling Nonmetrik (Studi Kasus: Data Persepsi dan Preferensi Konsumen Berdasarkan Merek Smartphone di Samarinda, Kalimantan Timur). Jurnal Ekponensial, vol 9, nomor 1, 2018, pp. 85-93.
Ramadhan, F.A. (2015). Analisis Positioning Top 4 Brand Smartphone Cina Berdasarkan Persepsi Konsumen di Kota Bandung Tahun 2015. Telkom, Bandung.

Rawi, S. N. (2018). Pengaruh Kepuasan Terhadap Loyalitas Konsumen Bunga Potong di Kota Bogor. Bogor: Institut Pertanian Bogor.

Sa'diyah, H. (2017). Pemerintah Ingin Florikultura Beri Kontribusi Besar pada PDB. Diakses pada 16 Desember 2019 dari Republika.co.id: https://republika.co.id/berita/otky9s383/ pemerintah-ingin-florikultura-berikontribusi-besar-pada-pdb.

Schiffman, L.G, Kanuk, L. L., \& Wisenblit, J. (2010). Perilaku konsumen. Edisi Global. Pearson, UK.

Sofiani, N. (2008). Analisi Preferensi Konsumen Terhadap Aglaonema. Bogor: Institut Pertanian Bogor.

Sujono, S. (2018). Laporan Kinerja Direktorat Jenderal Hortikultura TA. 2017. Jakarta: Kementerian Pertanian.

Sutojo, S. (2009). Manajemen Pemasaran. Edisi Kedua. PT. Damar Mulia Perkasa, Jakarta.Tarigan, H. (2017). Florikultura Indonesia 2017. Diakses pada 14 Desember 2019 dari hortikultura.pertanian.go.id: http://hortikultura.pertanian.go.id/?p=22 01.

Tinaprilla, N., \& Pratiwi, C. P. (2017). Menuju Agribisnis Indonesia yang Berdaya Saing. Bogor: Departemen Agribisnis 